$K_{\mathrm{m}}$ of the phosphodiesterase the transsynaptically induced increase of cyclic AMP content can be terminated even in the presence of persisting transsynaptic stimulation of adenylate cyclase. When the cyclic AMP content of chromaffin cells is enhanced for one hour or longer, the cytosol protein kinase-the receptor protein for cyclic AMP-is activated. This enzyme is formed of two subunits: a regulatory (R) and a catalytic (C) moiety; normally the inactive RC molecular configuration is the most abundant form of the enzyme. When cyclic AMP increases it binds to $\mathrm{R}$ and dissociates the $\mathrm{RC}$ complex. As a result, the protein kinase activity is enhanced because when $\mathrm{C}$ is dissociated from $\mathrm{R}$, it can express its catalytic activity at a maximum. Following persistent transsynaptic activation of chromaffin cells most of the protein kinase molecules in these cells are dissociated and the $\mathrm{C}$ form prevails. This increase of $\mathrm{C}$ subunits lasts for about $4 \mathrm{~h}$; however, the duration in the decrease in the number of RC molecules lasts for about $15 \mathrm{~h}$. A. Guidotti and collaborators (NIMH) have reported that the mechanism whereby the transsynaptically induced increase in $\mathrm{C}$ subunits is terminated is not by the reassociation of $\mathrm{C}$ with $\mathrm{R}$ but by the translocation of $\mathrm{C}$ from cytosol to subcellular structures including the nucleus. Chuang and E. Costa (NIMH) have shown that coincident with this translocation there is an increase in the synthesis of nuclear poly(A)-RNA. This elevation of mRNA synthesis rate is followed by an increased synthesis of tyrosine-3-mono-oxygenase (TH), the rate limiting enzyme for catecholamine biosynthesis. Also the synthesis of other medullary protein is enhanced at this time.

D. Russell (University of Arizona) also reported that the cyclic AMP content of adrenal medulla increases following the trans-synaptic activation of nicotinic receptors. She has shown that this second messenger response triggers the activation of ornithine decarboxylase which, in turn, accelerates the synthesis of ribosomal RNA.

R. A. Jungman and E. G. Kramias (Northwestern University Medical School, Chicago) have suggested that during hormonal regulation the RNA polymerase II activity can be modified through a phosphorylation of the enzyme by the action of a nuclear cyclic AMP-independent protein kinase.

I. Hanbauer (National Heart and Lung Institute, Bethesda) reported that when rats are maintained for about $1 \mathrm{~h}$ in an environment with low $\mathrm{O}_{2}$ tension, the TH activity of the carotid body increases after an interval of about $24 \mathrm{~h}$ following the stimulus. This increase in $\mathrm{TH}$ activity is also preceded by an activation of the cyclic AMP system. She reported that this chemical stimulus fails to change the $\mathrm{TH}$ in adrenal medulla or in superior cervical ganglia; moreover, she presented evidence that this $\mathrm{TH}$ activation does not require the participation of adrenergic or cholinergic mechanisms.

During this symposium, E. Giacobini (University of Connecticut, Storrs) and M. Otsuka (University of Tokyo) and others presented substantial experiments supporting the view that first messengers may include not only amino acids and their metabolites, but also polypeptides and adenosine triphosphate. The biochemical and functional implications of the participation in synaptic transmission of several molecular entities of transmitters were debated. It was also discussed whether the presence of such a pluralistic system of first messengers may require an updating of the Dale postulate that each neurone contains one and only one transmitter.

\section{Fighting erosion with soil conditioning}

from A. J. Low

The third international meeting on Soil Conditioners was held at the University of Ghent in Belgium on September $8-12$. The proceedings of the symposium (edited by M. De Boodt) will be published by the Faculty of Agricultural Sciences of the University of Ghent.

Soll is a three phase system-a porous heterogenous mixture of solids (minerals and organic matter), liquid (water containing many solutes) and gases. The structure of a soil is determined to a large extent by the soil organic matter which holds together the mineral skeleton. Soil structure is developed by the action of the root systems of permanent covering vegetation, such as that of grasslands. But when grassland is cultivated, the organic matter which has formed is quickly broken down and there is a corresponding structural collapse. The natural soil 'cements' include polysaccharides and polyuronides, and soil conditioners are synthetic replacements for these.

The first soil conditioners were probably vinyl acetate-maleic acid and hydrolysed polyacrylonitrile. Mixed with soil at a suitable moisture content they can bring about a much more stable structure which can last for ten years or so. Marked increases in crop yield have occurred when structure has been the limiting yield factor, but soil conditioners have not generally been adopted on a large scale because of their high cost.

What may be an important development is the application of soil conditioners in arid regions such as North Africa where to prevent the spread of the desert northwards an attempt is being made to establish a belt of trees (the Barrage Vert). The desert soil is largely devoid of organic matter, unaggregated and subject to wind erosion. It can be stabilised by building aggregates with soil conditioners and thus providing the conditions for trees and other plants to become established after planting which in turn helps to reduce wind erosion.

Suwardjo and Lenvain (Bogor Soil Science Institute, Indonesia) described how re-afforestation was being carried out in the humid tropics on strongly eroded areas where the soil structure was weak, by stabilising the soil in and around the planting holes of young trees. Once the trees are established the surrounding area tends to become revegetated.

W. Flaig (West Germany) related work on the biochemistry of soil organic matter to work on soil conditioning. He concerned himself especially with high molecular weight naturally occurring organic polymers and briefly discussed the possibility of converting lignosulphonates and other waste products into soil conditioners. The soil conditioning effects of lignin derivatives, sewage sludge and other waste products were also reported by Vasiljev (USSR), M. B. Kirkham (USA) and Knottnerus (Netherlands).

Fundamental studies of soil conditioners as materials for changing soil physical properties were described by De Bisschop (Ghent University) and Koenigs (Wageningen University) particularly liquid distribution in porous media.

Soil conditioners have been used to stabilise the backfill of pipe drains (Dierickz and Gabriels, Ghent University), in rice culture (Keersebilck and Muljadi, Bogor) and in stabilising sugar beet seed beds where soils are liable to cap.

The symposium concluded with an analysis of the papers and the conclusions to be drawn by Dudal (FAO) who suggested that soil conditioning might now be ready for application on a larger scale than hitherto. In contrast to the first symposium more than $50 \%$ of the papers in the third dealt with the use of waste products as soil conditioners. This was undoubtedly due to economics. The synthetic polymers used as soil conditioners in the 1950 s were even then very expensive and continue to be so.

The fourth symposium is to be held in Australia on August 16-23, 1976. 